\title{
Pilhas e Baterias
}

Sérgio P. J. Rodrigues

spjrodrigues@ci.uc.pt
Toda a gente usa pilhas e baterias. Nos rádios e brinquedos, nos carros, nos telemóveis e computadores, nas sondas e veículos espaciais, num sem número de equipamentos. Os nomes "pilha" e "bateria" vêm da sua organização: coisas agrupadas ou dispostas umas sobre as outras. Estes dispositivos são capazes de produzir corrente elétrica a partir de reações químicas de oxidação e de redução.

Antigamente, em casa, tínhamos as piIhas de zinco que podem ser explicadas pelas reações químicas seguintes:

$\mathrm{Zn}(\mathrm{s})+2 \mathrm{Cl}-(\mathrm{aq}) \rightarrow \mathrm{ZnCl}_{2}(\mathrm{~s})+2 \mathrm{e}^{-}$(oxidação)

$2 \mathrm{MnO}_{2}(\mathrm{~s})+2 \mathrm{NH}_{4} \mathrm{Cl}(\mathrm{aq})+\mathrm{H}_{2} \mathrm{O}(\mathrm{l})+2 \mathrm{e}^{-} \rightarrow \mathrm{Mn}_{2} \mathrm{O}_{3}(\mathrm{~s})$ $+2 \mathrm{NH}_{4} \mathrm{OH}(\mathrm{aq})+2 \mathrm{Cl}-(\mathrm{aq})$ (redução)

$\mathrm{Zn}(\mathrm{s})+2 \mathrm{NH}_{4} \mathrm{Cl}(\mathrm{aq})+\mathrm{H}_{2} \mathrm{O}(\mathrm{I})+2 \mathrm{MnO}_{2}(\mathrm{~s}) \rightarrow \mathrm{Mn}_{2} \mathrm{O}_{3}(\mathrm{~s})+$ $2 \mathrm{NH}_{4} \mathrm{OH}(\mathrm{aq})+\mathrm{ZnCl}_{2}(\mathrm{~s})($ global $)$

Estas pilhas, quando rebentavam, cheiravam a peixe devido à amónia (repare que um dos produtos da reação é $\mathrm{NH}_{4} \mathrm{OH}(\mathrm{aq})$ ).

Se se usar como eletrólito o próprio $\mathrm{ZnCl}_{2}$, a reação de redução é a seguinte (não serão usados estados físicos a partir daqui):

$2 \mathrm{MnO}_{2}+\mathrm{ZnCl}_{2}+\mathrm{H}_{2} \mathrm{O}+2 \mathrm{e}^{-} \rightarrow \mathrm{Mn}_{2} \mathrm{O}_{3}+\mathrm{Zn}(\mathrm{OH})_{2}+2 \mathrm{Cl}^{-}$

Assim, a reação que acontece na pilha é:

$\mathrm{Zn}+\mathrm{H}_{2} \mathrm{O}+2 \mathrm{MnO}_{2} \rightarrow \mathrm{Mn}_{2} \mathrm{O}_{3}+\mathrm{Zn}(\mathrm{OH})_{2}$

Neste caso, quando as pilhas rebentam observam-se resíduos brancos de hidróxido de zinco $\left(\mathrm{Zn}(\mathrm{OH})_{2}\right)$.

Por outro lado, nas baterias alcalinas as principais reações químicas são as seguintes:

$\mathrm{Zn}+2 \mathrm{KOH} \rightarrow 2 \mathrm{~K}^{+}+\mathrm{ZnO}+\mathrm{H}_{2} \mathrm{O}+2 \mathrm{e}^{-}$(oxidação) $2 \mathrm{MnO}_{2}+2 \mathrm{H}_{2} \mathrm{O}+2 \mathrm{e}^{-} \rightarrow 2 \mathrm{MnO}(\mathrm{OH})+2 \mathrm{OH}^{-}$(redução) $\mathrm{Zn}+2 \mathrm{MnO}_{2}+\mathrm{H}_{2} \mathrm{O} \rightarrow \mathrm{ZnO}+2 \mathrm{MnO}(\mathrm{OH})$ (global)

As pilhas referidas anteriormente só descarregam. Depois de descarregadas, devem ser recolhidas e recicladas.

Por outro lado, as baterias vulgares dos automóveis são de chumbo e recarregáveis, nas quais ocorrem as reações químicas seguintes:

$\mathrm{Pb}+\mathrm{SO}_{4}^{2-} \rightleftharpoons \mathrm{PbSO}_{4}+2 \mathrm{e}^{-}$(oxidação)

$\mathrm{PbO}_{2}+4 \mathrm{H}^{+}+\mathrm{SO}_{4}^{2-}+2 \mathrm{e}^{-} \rightleftharpoons 2 \mathrm{H}_{2} \mathrm{O}+\mathrm{PbSO}_{4}$ (redução)

$\mathrm{PbO}_{2}+\mathrm{Pb}+4 \mathrm{H}^{+}+2 \mathrm{SO}_{4}{ }^{2-} \rightleftharpoons 2 \mathrm{H}_{2} \mathrm{O}+2 \mathrm{PbSO}_{4}$ (global)
Nos automóveis, o alternador do motor (componente que transforma a energia cinética produzida pelo movimento do motor em energia elétrica) produz a energia elétrica necessária para alimentar o sistema elétrico do veículo, incluindo o carregamento e a manutenção da carga da bateria. No entanto, as baterias não são eternas e têm de ser substituídas. A reciclagem é mesmo obrigatória pois o chumbo é um metal pesado e prejudicial para o meio ambiente.

As baterias de níquel-cádmio também são recarregáveis. Neste caso, as reações que ocorrem são as seguintes:

$$
\begin{aligned}
& \mathrm{Cd}+2 \mathrm{OH}^{-} \rightleftharpoons \mathrm{Cd}(\mathrm{OH})_{2}+2 \mathrm{e}^{-} \text {(oxidação) } \\
& 2 \mathrm{NiO}(\mathrm{OH})+2 \mathrm{H}_{2} \mathrm{O}+2 \mathrm{e}^{-} \rightleftharpoons 2 \mathrm{OH}^{-}+2 \mathrm{Ni}(\mathrm{OH})_{2}(\text { redução }) \\
& 2 \mathrm{NiO}(\mathrm{OH})+2 \mathrm{H}_{2} \mathrm{O}+\mathrm{Cd} \rightleftharpoons \mathrm{Cd}(\mathrm{OH})_{2}+2 \mathrm{Ni}(\mathrm{OH})_{2}(\text { global })
\end{aligned}
$$

Mais uma vez, a reciclagem é obrigatória pois o níquel e o cádmio são tóxicos.

Nas baterias de ião de lítio usadas nos telemóveis ocorrem as reações químicas seguintes:

$$
\begin{aligned}
& x \mathrm{LiC}_{6} \rightleftharpoons x \mathrm{Li}^{+}+x \mathrm{C}_{6}+x \mathrm{e}^{-} \text {(oxidação) } \\
& \mathrm{Li}_{1-x} \mathrm{CoO}_{2}+x \mathrm{Li}^{+}+x \mathrm{e}^{-} \rightleftharpoons \mathrm{LiCoO}_{2} \text { (redução) } \\
& x \mathrm{LiC}_{6}+\mathrm{Li}_{1-x} \mathrm{CoO}_{2} \rightleftharpoons x \mathrm{C}_{6}+\mathrm{LiCoO}_{2} \text { (global) }
\end{aligned}
$$

O cobalto e o lítio não são tão tóxicos e poder-se-ia pensar que não seria tão premente reciclar. Mas sim, é preciso. É ambientalmente muito melhor e estes materiais são escassos.

As pilhas e baterias referidas são só algumas das que se podem encontrar no nosso dia a dia.

\section{Saiba mais em:}

Adaptado de Passeio químico à procura das pilhas e acumuladores, percursosquimicos.blogspot.com/2021/04/passeio-quimico-procura-daspilhas-e.html (acedido em 27 de julho de 2021).

Energizer Holdings, Inc., Battery Chemistry, energizer.com/about-batteries/ battery-chemistry (acedido em 27 de julho de 2021).

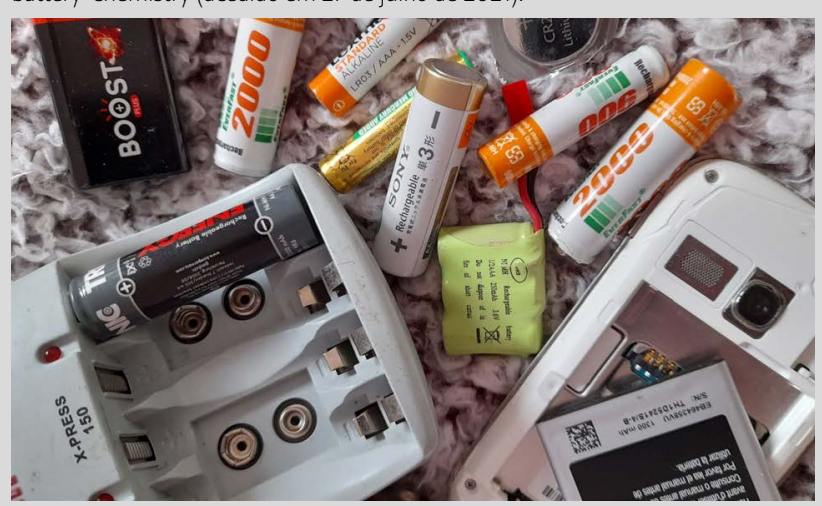

